\title{
ANÁLISE SANITÁRIA E FÍSICO-QUÍMICA E ADEQUAÇÃO BACTERIOLÓGICA DO QUEIJO MINAS ARTESANAL PRODUZIDO EM DUAS PROPRIEDADES
}

\section{SANITARY AND PHYSICOCHEMICAL ANALYSIS AND BACTERIOLOGICAL ADEQUACY OF MINAS ARTISANAL CHEESE PRODUCED IN TWO PROPERTIES}

\author{
Driene Bastos Soares ${ }^{1}$ \\ Guilherme Paz Monteiro ${ }^{1}$ \\ Belchiolina Beatriz Fonseca ${ }^{1}$ \\ Eduardo Almeida Freitas ${ }^{1}$ \\ Eliane Pereira Mendonça ${ }^{1}$ \\ Roberta Torres de Melo ${ }^{2}$ \\ Jocasta Rodrigues lasbeck ${ }^{1 *}$ \\ Daise Aparecida Rossi ${ }^{1}$ \\ ${ }^{1}$ Universidade Federal de Uberlândia, Uberlândia, MG, Brasil. \\ 2Universidade de Uberaba, Uberaba, MG, Brasil. \\ *Autora para correspondência: iasbeck_jocasta@hotmail.com
}

\section{Resumo}

Objetivou-se descrever as condições higiênico-sanitárias de queijarias artesanais, determinar os parâmetros físico-químicos, bacteriológicos e o período mínimo de maturação que garanta a inocuidade de queijos minas artesanais produzidos em Uberlândia-MG. Foram analisados, até aos 26 dias de maturação, queijos de duas propriedades, antes e após treinamento em boas práticas, totalizando 10 lotes (fabricações) com 12 queijos cada. Foram realizadas análises físico-químicas e bacteriológicas nos queijos e análises bacteriológicas em amostras ambientais. Até 26 dias de maturação, o queijo foi classificado como gordo e de baixa umidade, mas, considerando a maturação até 10 dias (período de comercialização usual), são gordos com média umidade. O tempo de maturação influenciou nos índices físico-químicos, com exceção da gordura no extrato seco. Análises bacteriológicas ambientais demonstraram higiene deficiente e falhas ou ausência no tratamento da água. A maturação e o treinamento influenciaram na redução de coliformes totais e e. coli, mas não de Staphylococcus coagulase positiva, não sendo possível determinar um período de maturação mínimo que garantisse o atendimento à legislação. As análises físico-químicas demonstraram variações esperadas, como a redução do percentual de umidade, e as análises bacteriológicas refletiram o treinamento aplicado aos manipuladores, já que houve redução nas contagens de coliformes totais e E. coli. Contudo, para garantir a inocuidade do produto, é necessário um conjunto de ações que incluem reforço e repetição dos treinamentos, registro das atividades, rastreabilidade, associadas ao monitoramento e fiscalização regular.

Palavras-chave: maturação; parâmetros físico-químicos; qualidade bacteriológica; queijaria.

\section{Abstract}


The aim of this study was to describe the sanitary conditions of artisanal dairies, to determine physicochemical and bacteriological parameters, and the minimum maturation period to guarantee the safety of Minas Artisanal cheese produced in Uberlândia, Minas Gerais state. The analyzes were performed up to the 26 days of maturation, on cheese from two properties, before and after training on good practices, totaling 10 lots (productions) with 12 cheeses each. Physicochemical and bacteriological analyzes were performed on cheeses and bacteriological analyzes in environmental samples. Up to 26 days of maturation, the cheese was classified as fat and low moisture, but considering maturation up to ten days (usual commercialization period), cheese is fat with medium moisture. The maturation time influenced the physicochemical indices, except for the fat in the dry matter. Environmental bacteriological analyzes demonstrated poor hygiene and faults or absence in water treatment. Maturation and training influenced the reduction of total coliforms and E. coli, but not Staphylococcus coagulase positive, and it was not possible to determine a minimum maturation period that would guarantee compliance with the legislation. The physicochemical analysis showed expected variations, such as the reduction of the percentage of moisture and the bacteriological analyzes reflected the training applied to the manipulators, since there was a reduction in the counts of total coliforms and E. coli; however, to guarantee the innocuity of the product, set of actions should be applied, including reinforcement and repetition of training, recording of activities, traceability, associated with regular monitoring and inspection.

Keywords: bacteriological quality; cheesemaking; maturation; physicochemical parameters.

Recebido em: 01 de julho de 2015.

Aceito em: 14 de maio de 2018

\section{Introdução}

Os queijos artesanais são alimentos muito manipulados e, por esse motivo, passíveis de contaminação, especialmente de origem bacteriológica. Essa condição é agravada pelo uso do leite cru, principalmente quando não há emprego de boas práticas ou não são maturados por período suficiente. A pesquisa bacteriológica permite, muitas vezes, entender as condições sob as quais um produto foi produzido, sendo fundamental na produção de alimentos seguros e na garantia da saúde do consumidor ${ }^{(1)}$.

A maturação do queijo é um processo complexo, envolvendo a formação de componentes do aroma e sabor por diferentes vias, além de possuir papel importante na garantia da segurança alimentar, uma vez que pesquisas têm demonstrado a sua influência na redução das contagens de coliformes totais, E. coli e $S$. aureus $^{(2)}$, Brucella abortus ${ }^{(3)}$ e Micobacterium bovis ${ }^{(4)}$. Essa melhoria na qualidade bacteriológica está associada à diminuição da água livre para atuação de micro-organismos, ou seja, redução na atividade de água (Aw) do queijo, aliada à modificação do teor de sal, que compreendem parâmetros primordiais para o controle da microbiota e dos processos bioquímicos da maturação ${ }^{(2)}$.

Além da maturação, outros fatores influenciam diretamente na qualidade bacteriológica dos queijos artesanais, como a sanidade dos animais que compõem o rebanho e o uso de práticas higiênicosanitárias em toda a cadeia de produção ${ }^{(5)}$. De forma indireta, a umidade, o teor de sal e outras características físico-químicas também podem influenciar na sua qualidade bacteriológica ${ }^{(6)}$ e essa relação deve ser investigada. Em queijos artesanais, geralmente os parâmetros bacteriológicos, químicos e sensoriais são influenciados pela tecnologia de fabricação $\operatorname{empregada}^{(1)}$, que são 
peculiares em cada região produtora.

Vários estudos sobre a qualidade bacteriológica desses alimentos demonstraram que os mesmos se encontram fora dos parâmetros bacteriológicos exigidos pela legislação ${ }^{(2,6,7)}$. A maioria desses estudos avalia a qualidade bacteriológica do queijo Minas artesanal em relação ao período de maturação em locais tradicionais de produção, como a região do Serro e da Canastra ${ }^{(2,8,9)}$.

Essa regionalização das avaliações é importante, já que as formas de produção, qualidade do leite e o microclima influenciam diretamente nas características físico-químicas e bacteriológicas ${ }^{(10)}$. Dessa forma, são necessários estudos nas diferentes regiões produtoras para se conhecer as particularidades de cada região e determinar fatores que possam garantir que os queijos comercializados não tragam perigos à saúde do consumidor.

Objetivou-se avaliar a composição físico-química, as condições higiênico-sanitárias de produção e a adequação bacteriológica à legislação de queijos minas artesanais produzidos no município de Uberlândia-MG e, ainda, determinar se há um período mínimo de maturação que garanta, do ponto de vista bacteriológico, a segurança do seu consumo.

\section{Material e Métodos}

Foram avaliados queijos produzidos em duas propriedades rurais produtoras de queijos artesanais, indicadas pela Prefeitura Municipal de Uberlândia, por serem as únicas cadastradas na região. Os queijos foram coletados e analisados durante o período de agosto/2012 a dezembro/2012, momentos em que houve a liberação pela prefeitura para realização das colheitas. O experimento constou de três etapas distintas: a) coleta de queijos para análise; b) treinamento em boas práticas de fabricação; e c) coleta de amostras para análise. As análises foram realizadas no Laboratório de Biotecnologia Animal Aplicada da Faculdade de Medicina Veterinária da Universidade Federal de Uberlândia.

O treinamento foi expositivo e prático e seu conteúdo oferecido aos produtores na forma de uma apostila, para consulta posterior.

Antes do treinamento em boas práticas, foram analisados queijos de dois lotes de cada um dos produtores e, após o treinamento, três lotes foram analisados. Cada lote foi composto de 12 queijos, que eram mantidos nas propriedades nas condições de maturação usuais. Após 1, 3, 5, 8, 10, 12, 15, 17, 19, 22, 24 e 26 dias de maturação, era coletado um queijo em sua embalagem original para análises de coliformes totais, E. coli, Staphylococcus coagulase positiva, umidade, acidez titulável, gordura, gordura no extrato seco, cloreto de sódio, proteínas e cinzas. Os queijos maturados por 1, 8, 15 e 22 dias também foram avaliados quanto à presença de Salmonella spp. e Listeria monocytogenes (Figura $1)$.

No dia da fabricação de cada um dos lotes de queijos, foram também coletadas para análise de coliformes, amostras de leite, água, soro-fermento, mãos dos manipuladores, balde da ordenha, das bancadas, das prateleiras e das formas do queijo.

Os queijos foram coletados em sacos plásticos de primeiro uso. Ao chegar no laboratório, a embalagem era higienizada externamente com álcool etílico $70 \%$ e, em fluxo laminar, retirava-se 25 g para análises de coliformes totais e E. coli e Staphylococcus coagulase positiva para a diluição inicial em $225 \mathrm{~mL}$ de solução de citrato $0,1 \%$ estéril (Synth). Outras duas porções de $25 \mathrm{~g}$ eram adicionadas em água peptonada tamponada (Oxoid) e caldo Listeria (DuPont Qualicont) destinadas 
ao pré-enriquecimento e posterior análise de Salmonella spp. e Listeria monocytogenes. O restante do queijo foi utilizado para as análises físico-químicas e pesquisa de material estranho.

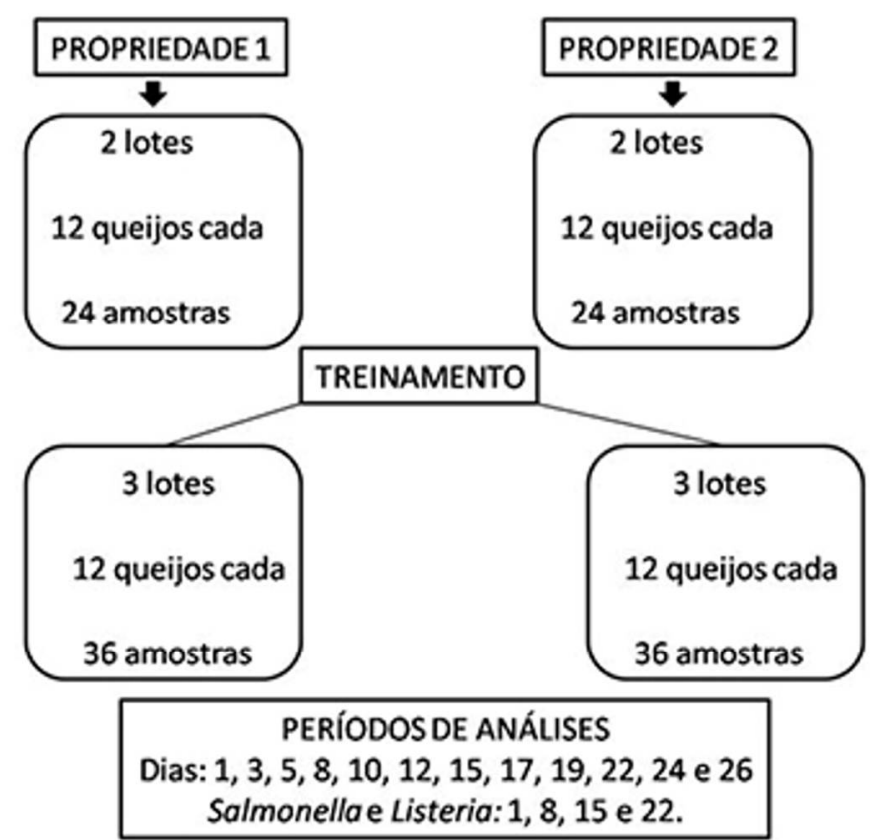

Figura 1. Fluxograma de procedimento de coleta das amostras antes e após treinamento e períodos de análises físico-químicas e microbiológicas.

Para a enumeração de coliformes totais e $E$. coli nos queijos foi o utilizado o método cromogênico Compact Dry EC (Nissui Pharmaceutical Co. Ltd.), incubado a $35^{\circ} \mathrm{C} \pm 2{ }^{\circ} \mathrm{C}$ por 24 horas. Coliformes totais e termotolerantes no leite, água, soro-fermento e $s w a b s$ de equipamentos foram quantificados pela técnica do número mais provável (NMP), realizadas de acordo com Silva et al. ${ }^{(11)}$.

A enumeração de Staphylococcus coagulase positiva nos queijos e sua presença/ausência nas mãos dos manipuladores foram realizadas em ágar seletivo Baird Parker (Oxoid), incubado a $35^{\circ} \mathrm{C}$ por 48 horas, com confirmação pela prova da coagulase e catalase ${ }^{(12)}$.

A presença/ausência de Salmonella spp. e Listeria monocytogenes em $25 \mathrm{~g}$ de queijo ou $25 \mathrm{~mL}$ do leite foi realizada pelo método molecular Bax System (Dupont Qualicon®), aprovado pela AOAC 100.201 e AFNOR QUA 13/3-11/02(13) e pelo MAPA, conforme IN 40 de 12/12/2005(14) e Bax for Listeria monocytogenes 24E (Dupont Qualicon ${ }^{\circledR}$ ), aprovado para análise de alimentos pela AOAC 080901 e AFNOR QUA-18/05-07/08 ${ }^{(13)}$ e pelo MAPA IN n 40 ${ }^{(14)}$, respectivamente.

Para auxiliar na análise das condições sanitárias do local, bactérias mesófilas, em leite e água foram cultivadas em ágar PCA - agar plate count (Difco), incubado a $35^{\circ} \mathrm{C}$ por 48 horas. Para quantificação de bactérias láticas no soro-fermento, foi utilizado o ágar MRS (Merck) sob anaerobiose, a $30^{\circ} \mathrm{C}$ por 48 horas, a fim de verificar a viabilidade da microbiota desejável presente. As técnicas foram realizadas conforme recomendações de Silva et al. ${ }^{(11)}$.

Para a determinação da umidade, gordura, gordura no extrato seco, acidez titulável, cloretos, cinzas e proteína total foram utilizados os métodos oficiais descritos na Instrução Normativa 68, de 12 de dezembro de $2006^{(14)}$. A proteína total (PT) foi determinada de modo indireto, multiplicando-se o percentual de nitrogênio total (NT) pelo fator 6,38, indicado para proteína derivada de leite ${ }^{(12)}$.

Os resultados bacteriológicos dos ensaios antes e depois dos treinamentos foram tabulados, 
transformados em $\log _{10}$ e testados quanto à normalidade pelo teste de Kolmogorov-Smirnov. O teste $t$ de Student foi utilizado para verificar diferenças entre dados pareados com $95 \%$ de confiança. As correlações de Pearson e Spearman foram utilizadas para verificar a relação entre os resultados obtidos nas contagens de bioindicadores e os parâmetros físico-químicos ao longo da maturação. Os procedimentos foram realizados conforme orientações ${ }^{(15)}$ utilizando o programa GraphPad prism 5.0.

\section{Resultados e Discussão}

As visitas às duas propriedades produtoras dos queijos artesanais mostraram deficiências relacionadas à estrutura física e práticas sanitárias adotadas nas duas unidades produtoras de queijos artesanais. Quanto às estruturas físicas, as principais falhas observadas foram: inadequação do local de ordenha e falhas de vedação na queijaria contra animais e insetos. Quanto às condições sanitárias, podem-se destacar: a não utilização de boas práticas na obtenção do leite, insuficiente higienização das mãos e uso de água sem tratamento. Assim, o treinamento dos produtores foi focado em procedimentos que visavam corrigir as principais não conformidades observadas e nas recomendações de boas práticas preconizados pela Portaria $\mathrm{n}^{\mathrm{o}} 523$, de 3 de julho de $2002^{(16)}$.

Os índices médios percentuais dos parâmetros físico-químicos dos queijos, considerando os resultados médios das análises realizadas após $1,3,5,8,10,12,15,17,19,22,24$ e 26 dias de maturação foram: $2,08 \pm 0,59 \%$ de cloreto de sódio, $27,46 \pm 3,17 \%$ de proteínas, $5,34 \pm 0,83 \%$ de cinzas, $30,10 \pm 3,67 \%$ de gordura e $35,39 \pm 8,11 \%$ de umidade. A gordura no extrato seco (GES) foi de $47,15 \% \pm 4,63 \%$ e a acidez de $1,97 \pm 1,42$ gramas de ácido láctico.

Utilizando o padrão de identidade e qualidade de leite e derivados determinados na Portaria $\mathrm{n}^{\mathrm{o}} 146$ de $1996^{(17)}$, os queijos maturados por até 26 dias foram classificados como gordos $(45 \%<$ GES $<$ $59,9 \%)$ e de baixa umidade ( $<35,9 \%)$. Entretanto, nos queijos maturados até dez dias, que é na prática o período máximo em que são comercializados, a classificação passa a ser de gordos com média umidade, por apresentarem GES de $45,9 \%$ e umidade de $43 \%$, como média neste período. Outros estudos também classificaram queijos artesanais maturados em temperatura ambiente das regiões do Serro e da Canastra como sendo gordo e de média umidade ${ }^{(2,10)}$.

A porcentagem de cloreto de sódio em queijos produzidos em regiões tradicionais de Minas Gerais como Serra da Canastra e Araxá apresentaram médias de 1,96\% e 2,06, respectivamente ${ }^{(18)}$, semelhante ao encontrado no presente estudo $(2,08 \pm 0,59 \%)$.

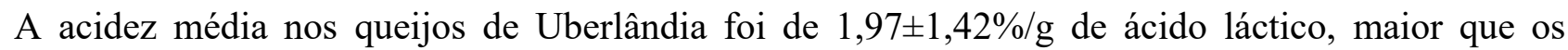
relatados por Resende et al. ${ }^{(10)}$, Araújo ${ }^{(18)}$, Martins $^{(19)}$ e Silva $^{(20)}$, que foram respectivamente de $0,72 \%$ na região da Canastra, 0,77\% em queijos artesanais de Araxá, 0,99\% no Serro e 1,21\% em outros municípios da Canastra. Por ser prensado manualmente, o queijo Minas artesanal apresenta retenção de soro desuniforme, o que interfere na quantidade de lactose eliminada. Assim, diferentes teores de lactose podem ser convertidos em ácido láctico nos queijos por bactérias lácticas provenientes do leite, soro-fermento e ambiente ${ }^{(10)}$.

A porcentagem média de gordura nos queijos de Uberlândia, de 35,39 $\pm 8,11$, foi superior aos $28 \%$, $27,62 \%$ e $23,6 \%$, encontrados por Oliveira et. al. ${ }^{(21)}$ em queijos produzidos no Serro, Cerrado e Canastra, respectivamente. Também foi maior que queijos produzidos em Araxá, com porcentagem média de $28,29 \%{ }^{(18)}$. O inverso ocorreu com a gordura no extrato seco (GES), que foi inferior aos 
resultados obtidos nas regiões do Serro, Canastra e Cerrado, de 52,95\%, 52,67\% e 51,62\% respectivamente ${ }^{(20)}$ e em Araxá, com 50,83\% ${ }^{(18)}$. Dos componentes do leite, o teor de gordura é o que mais varia em função da alimentação e por outros fatores como a raça e genética ${ }^{(21)}$.

A média de umidade neste estudo, de $35,39 \pm 8,11 \%$, foi inferior às observadas por Araújo ${ }^{(18)} \mathrm{e}$ Oliveira et al. ${ }^{(21)}$, nas regiões de Araxá, Serro, Canastra e Cerrado, cujos valores foram de 44,32\%, $47,38 \%, 44,9 \%$ e 46,51\%. O tamanho dos grãos, vigor e tempo de mexedura da coalhada durante o processo de fabricação influenciam no teor de umidade e outros componentes do leite retidos na coalhada $^{(23)}$. Durante as visitas às propriedades de Uberlândia, não foi observado nenhum controle do tamanho dos grãos da coalhada durante o corte. Esse fator é importante, pois quanto menor o grão, menor será o teor de umidade do queijo ${ }^{(1)}$.

O teor médio de cinzas dos queijos, de 5,34 $\pm 0,83$, encontra-se acima do relatado por Lempk ${ }^{(22)} \mathrm{em}$ Montes Claros que foi de 4,05\%. Rocha ${ }^{(23)}$ afirma que o teor de cinzas é de grande importância na textura final dos queijos. A massa de queijo é um conjunto, no qual o cálcio forma a estrutura, atuando como elemento de ligação.

Comparações na composição de queijos de distintas regiões devem ser avaliadas com cautela, devendo-se levar em consideração, além das diferenças na tecnologia de fabricação, a composição do leite e o tempo de maturação em que os queijos foram analisados. Este conhecimento é importante para entender as variações regionais e, ainda, permitir estabelecer padrões de identidade em cada região certificada por período de maturação. O tempo mínimo de maturação, previamente estabelecido como seguro, pode ser correlacionado a índices físico-químicos, como a umidade limite menor ou igual a 45,9\%, que é o padrão estabelecido pelo Instituto Mineiro de Agropecuária - IMA no Decreto $\mathrm{n}^{\mathrm{o}} 44.864$, de $1^{\mathrm{o}}$ de agosto de $2008^{(24)}$. Entretanto, somente a avaliação contínua permitirá entender se apenas um ou alguns desses índices físico-químicos são suficientes para garantir a segurança do consumo de queijos artesanais. E, ainda, levar em consideração que a maioria dos produtores não respeita o período mínimo de maturação necessário para adquirir a umidade estabelecida, pois alegam que há alteração no sabor e textura preferidos pelos compradores. Essa atitude, aliada à fiscalização insuficiente, pode levar riscos aos consumidores.

As porcentagens de cloreto, proteína, cinzas, gordura, acidez titulável (apenas na seca) e umidade foram influenciadas pelo tempo de maturação $(\mathrm{p}<0,05)$, a única exceção foi a gordura no extrato seco (GES), no qual não foi observada correlação ( $>0,05)$. Houve aumento dos teores de cloreto, proteínas, gorduras e acidez e diminuição da umidade ao longo da maturação. Dores et al. ${ }^{(2)} \mathrm{e}$ Martins $^{(19)}$ também concluíram que o tempo de maturação influenciou nos mesmos parâmetros observados nos queijos artesanais de Uberlândia. Esse resultado era esperado, e provavelmente, é consequência da perda de água que ocorre em queijos maturados sem embalagem e em temperatura ambiente.

Os resultados das análises bacteriológicas realizadas no leite, água e soro-fermento demonstraram a pouca padronização nos procedimentos de higiene na ordenha e na produção dos queijos, além de falhas ou ausência na qualidade/tratamento da água.

Todas as análises realizadas na água resultaram em contagens inadequadas de acordo com a legislação, o que determina que coliformes totais e termotolerantes devem estar ausentes em $100 \mathrm{~mL}$ da amostra e que a contagem máxima de bactérias mesófilas deve ser de $5,0 \times 10^{2} \mathrm{UFC} / \mathrm{mL}^{(25)}$. O treinamento realizado, que orientou sobre a importância da qualidade da água para a inocuidade do queijo e formas de tratamento da mesma, não influenciou nos resultados. Isso demonstra que treinamentos devem ser reforçados periodicamente e acompanhados de monitoramento pelos órgãos 
de fiscalização.

Martins $^{(19)}$ verificou que, das propriedades da região do Serro, $62,5 \%$ se encontram fora dos padrões exigidos pela legislação em relação à qualidade da água.

Não foi observada a presença de Listeria monocytogenes e Salmonella spp. em nenhuma das amostras de leite, resultado que concorda com Santos ${ }^{(26)}$, que analisou leite utilizado na fabricação de queijos artesanais na microrregião do Serro-MG.

Todas as amostras de leite apresentaram altas contagens para E. coli, coliformes totais e bactérias mesófilas, independente do treinamento sobre obtenção higiênica do leite. Antes do treinamento, as contagens médias foram de $420 \mathrm{NMP} / 100 \mathrm{~mL}$ para $E$. coli, $880 \mathrm{NMP} / 100 \mathrm{~mL}$ para coliformes totais e 2,7x $10^{6}$ UFC. $\mathrm{mL}^{-1}$ para mesófilas. Posterior ao treinamento, obteve-se $410 \mathrm{NMP} / 100 \mathrm{~mL}$ de E.coli,

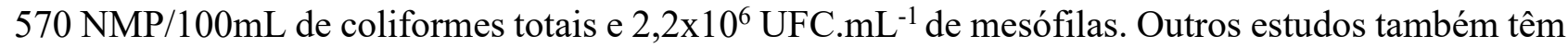
relatado contaminações por $E$. coli, coliformes totais e mesófilas no leite utilizado para a fabricação dos queijos artesanais acima dos padrões recomendados ${ }^{(19,26)}$.

As contagens de bioindicadores no leite deste estudo sinalizam para condições inadequadas na sua obtenção e/ou no seu armazenamento, incluindo o tempo máximo recomendado pela legislação entre a ordenha e fabricação dos queijos, que é de no máximo 90 minutos $^{(27)}$. De acordo com Silva et al. ${ }^{(28)}$, as principais fontes de contaminação do leite são: a água residual do latão, latão, resfriador, tetos, três primeiros jatos, teteiras, baldes e mãos do ordenhador. Todos estes itens foram destacados no treinamento em boas práticas.

Assim como o leite utilizado na fabricação, o soro-fermento também apresentou altas contagens de bioindicadores, que variaram de 940 NMP.ml-1 para E. coli, $1100 \mathrm{NMP} .100 \mathrm{~mL}^{-1}$ para coliformes totais e $3,3 \times 10^{4} \mathrm{UFC} . \mathrm{mL}^{-1}$ para bactérias láticas antes do treinamento e $>1100 \mathrm{NMP} . \mathrm{ml}^{-1}$ para E. coli e coliformes totais, e 9,0 x106 UFC. $\mathrm{mL}^{-1}$ para bactérias láticas, após o treinamento. Martins ${ }^{(19)}$ encontrou resultados semelhantes com alta contaminação no soro-fermento, 3,21 Log UFC.mL-1 (1,6 x $10^{3}$ UFC.mL $\left.{ }^{-1}\right)$ para coliformes totais e 2,2 Log UFC.mL $L^{-1}\left(1,6 \times 10^{2} \mathrm{UFC} . \mathrm{mL}^{-1}\right)$ para E. coli. Assim, apesar de o soro-fermento possuir a função de substituir o fermento láctico nas produções artesanais, pode representar uma importante fonte de contaminação do queijo. Apesar da presença de coliformes, o soro-fermento apresentou predominância de bactérias láticas, que, de acordo com Santos ${ }^{(26)}$, tem como uma das funções esperadas, a inibição de contaminantes indesejáveis por exclusão competitiva.

De acordo com Medeiros et al. ${ }^{(29)}$, as mãos são uma das principais fontes de contaminação dos queijos por Staphylococcus. Neste estudo, as mãos dos manipuladores apresentaram coliformes totais em 3/5 (60\%) amostras antes do treinamento e 5/5 (100\%) após; Staphylococcus coagulase positiva estavam presentes em 1/5 (20\%) amostras antes e 4/5 (80\%) após o treinamento em boas práticas de manipulação.

Foram observadas mais amostras positivas para E. coli e Staphylococcus coagulase positiva nas mãos dos manipuladores após o treinamento. Esse resultado não era esperado, mas reflete a realidade de treinamentos esporádicos, sem fiscalização posterior, indicando que isoladamente treinamentos não são suficientes para alteração significativa no comportamento dos produtores. $\mathrm{O}$ mesmo foi observado por Araújo ${ }^{(18)}$, que entrevistou produtores de queijos artesanais e constatou que $43 \%$ (16/37) deles, mesmo já havendo participado de algum tipo de treinamento, não utilizavam o conhecimento apreendido na sua prática diária.

E. coli foi identificada em todas as amostras ambientais, sendo as maiores contagens médias observadas antes do treinamento, na prateleira de madeira utilizada para a maturação dos queijos e 
formas de queijo (ambas, $280 \mathrm{NMP} \cdot \mathrm{g}^{-1}$ ). Apesar de os resultados indicarem redução nas contagens após o treinamento em boas práticas (120 e 3,1 NMP.g ${ }^{-1}$ para prateleira e forma, respectivamente), não foi suficiente para prevenir sua presença. Para o mesmo micro-organismo, os números antes e após treinamento, respectivamente, na bancada utilizada para manipulação do queijo $(5,1$ e 3,1 NMP.cm $\left.{ }^{2}\right)$ e balde usado para coagulação $\left(2,0\right.$ e 5,3 NMP.cm $\left.{ }^{2}\right)$ demonstraram que o treinamento não foi suficiente para excluir essas fontes como contaminantes dos queijos.

Os resultados obtidos neste estudo, aliado ao de Araújo ${ }^{(18)}$, reforçam a necessidade de treinamentos contínuos, monitoramento e fiscalização na obtenção higiênica do leite, particularmente em produtores de queijos artesanais, nos quais não há nenhuma etapa posterior capaz de garantir individualmente os riscos ao consumidor.

A presença de Listeria monocytogenes não foi observada em nenhuma das amostras de queijo e Salmonella spp. foi detectada em somente uma das amostras (1/40). Essa amostra foi analisada no primeiro dia de maturação e era proveniente do terceiro lote analisado após o treinamento para BPF.

Baixa incidência ou não identificação de Listeria monocytogenes e Salmonella spp. tem sido observada em queijos artesanais em diferentes estudos realizados no Brasil, apesar do uso de leite não pasteurizado para a fabricação ${ }^{(2,10,19)}$. Costa et al. ${ }^{(30)}$ afirmam que a competitividade das bactérias do ácido lático (BAL) durante o processo de maturação pode resultar na redução ou ausência de alguns patógenos.

A Tabela 1 mostra as contagens médias de E. coli, coliformes totais e SCP-Staphylococccus coagulase positiva em log UFC. $\mathrm{g}^{-1}$ ao longo da maturação antes e após treinamento em BP - boas práticas na produção do leite e fabricação. As contagens de coliformes totais e E. coli diminuíram significativamente nos queijos fabricados após o treinamento e implantação de $\mathrm{BP}(\mathrm{p}<0,05)$. Já para Staphylococcus coagulase positiva, não houve diferença significativa antes e após o treinamento.

A contaminação nos queijos, principalmente nos períodos iniciais da maturação, são consequentes do somatório da contaminação inicial do leite e da manipulação. Posteriormente, outros fatores irão interferir na sua multiplicação, como o tempo e a temperatura, presença de competidores, entre outros.

A redução dos números de $E$. coli e coliformes totais após o treinamento em BP foram gradativas e influenciadas pelo período de maturação $(p<0,05)$. Entretanto, somente aos 12 dias atingiram o padrão exigido pela legislação (máximo $\left.10^{2} \mathrm{UFC}_{\mathrm{g}} \mathrm{g}^{-1} ; 2,00 \mathrm{Log} \mathrm{UFC} . \mathrm{g}^{-1}\right)^{(22)}$. Assim como para as contagens de E. coli, os números de coliformes totais foram reduzidos durante a maturação em temperatura ambiente, porém, já aos três dias, se mostraram adequados aos padrões da legislação (máximo $10^{3}$ UFC. $g^{-1} ; 3,00$ Log UFC. $\left.g^{-1}\right)^{(24)}$. Este período de maturação, suficiente para a redução a níveis aceitáveis de coliformes totais, só foi observado ao final de sete semanas por Santos ${ }^{(26)}$. Martins ${ }^{(19)}$ verificou que eram necessários seis dias para a redução das contagens em dois ciclos log. Neste estudo, a redução de dois ciclos log ocorreu aos dois dias para E. coli, 10 dias para coliformes totais e não foi observada para Stphylococcus coagulase positiva (SCP).

Neste estudo, o treinamento e o tempo de maturação não foram suficientes para reduzir $(\mathrm{p}>0,05)$ os números de Staphylococcus coagulase positiva. Apesar de algumas amostras apresentarem contagens dentro do padrão exigido, que é $\leq 2,0 \mathrm{Log} U \mathrm{UFC} \cdot \mathrm{g}^{-1}\left(100 \mathrm{UFC} \cdot \mathrm{g}^{-1}\right)^{(16)}$ as contagens apresentaram alta variabilidade e não houve correlação entre as contagens e o tempo de maturação de queijos. Resultado semelhante foi encontrado com Santos ${ }^{(26)}$, já Martins ${ }^{(19)}$ e Dores et al. ${ }^{(2)}$ conseguiram determinar períodos de 17 e 22 dias de maturação respectivamente para o controle deste patógeno.

A variação nas contagens de SCP encontradas no presente trabalho é provavelmente, consequência 
de falhas no controle da mastite, além da presença desse micro-organismo nas mãos dos manipuladores.

Além disso, o consumo dos queijos em que os números de Staphylococcus coagulase positiva são reduzidos a níveis aceitáveis podem representar perigo ao consumidor. Muitas cepas possuem a capacidade de produzir enterotoxinas e as condições de manutenção dos queijos artesanais favorecem sua produção. As enterotoxinas estafilocócicas são termoestáveis ${ }^{(31)}$.

Tabela 1. Contagens de bioindicadores em queijos minas artesanal ao longo da maturação (dias) em Uberlândia-MG, antes e após treinamento BP (agosto a dezembro/2012)

\begin{tabular}{ccccccc}
\hline \multirow{2}{*}{$\begin{array}{c}\text { Dias de } \\
\text { maturação }\end{array}$} & \multicolumn{2}{c}{$E$. coli } & \multicolumn{2}{c}{ Coliformes totais } & \multicolumn{2}{c}{$S$. coagulase positiva } \\
\cline { 2 - 7 } & Antes & Após & Antes & Após & Antes & Após \\
\hline 1 & $5,58^{\mathrm{a}}$ & $3,41^{\mathrm{b}}$ & $6,88^{\mathrm{a}}$ & $3,86^{\mathrm{b}}$ & $1,00^{\mathrm{a}}$ & $1,57^{\mathrm{a}}$ \\
3 & $3,62^{\mathrm{a}}$ & $2,71^{\mathrm{b}}$ & $6,14^{\mathrm{a}}$ & $* 2,73^{\mathrm{b}}$ & $2,47^{\mathrm{a}}$ & $2,34^{\mathrm{a}}$ \\
5 & $4,85^{\mathrm{a}}$ & $2,19^{\mathrm{b}}$ & $5,50^{\mathrm{a}}$ & $2,27^{\mathrm{b}}$ & $1,92^{\mathrm{a}}$ & $3,42^{\mathrm{a}}$ \\
8 & $3,36^{\mathrm{a}}$ & $2,21^{\mathrm{b}}$ & $5,24^{\mathrm{a}}$ & $2,48^{\mathrm{b}}$ & $1,00^{\mathrm{a}}$ & $1,57^{\mathrm{a}}$ \\
10 & $4,13^{\mathrm{a}}$ & $2,19^{\mathrm{b}}$ & $4,88^{\mathrm{a}}$ & $2,62^{\mathrm{b}}$ & $1,00^{\mathrm{a}}$ & $2,80^{\mathrm{a}}$ \\
12 & $4,12^{\mathrm{a}}$ & $* 2,00^{\mathrm{b}}$ & $5,99^{\mathrm{a}}$ & $2,14^{\mathrm{b}}$ & $2,03^{\mathrm{a}}$ & $3,08^{\mathrm{a}}$ \\
15 & $3,54^{\mathrm{a}}$ & $2,00^{\mathrm{b}}$ & $4,19^{\mathrm{a}}$ & $2,18^{\mathrm{b}}$ & $1,00^{\mathrm{a}}$ & $2,66^{\mathrm{a}}$ \\
17 & $2,78^{\mathrm{a}}$ & $2,00^{\mathrm{b}}$ & $3,72^{\mathrm{a}}$ & $2,14^{\mathrm{b}}$ & $1,00^{\mathrm{a}}$ & $1,53^{\mathrm{a}}$ \\
19 & $3,99^{\mathrm{a}}$ & $2,00^{\mathrm{b}}$ & $4,67^{\mathrm{a}}$ & $2,00^{\mathrm{b}}$ & $2,62^{\mathrm{a}}$ & $1,43^{\mathrm{a}}$ \\
22 & $2,85^{\mathrm{a}}$ & $2,00^{\mathrm{b}}$ & $3,80^{\mathrm{a}}$ & $2,00^{\mathrm{b}}$ & $2,31^{\mathrm{a}}$ & $1,79^{\mathrm{a}}$ \\
24 & $2,41^{\mathrm{a}}$ & $2,00^{\mathrm{b}}$ & $2,42^{\mathrm{a}}$ & $2,00^{\mathrm{b}}$ & $2,23^{\mathrm{a}}$ & $2,84^{\mathrm{a}}$ \\
26 & $2,18^{\mathrm{a}}$ & $2,00^{\mathrm{b}}$ & $2,72^{\mathrm{a}}$ & $2,00^{\mathrm{b}}$ & $3,51^{\mathrm{a}}$ & $1,00^{\mathrm{a}}$ \\
\hline $\begin{array}{l}\text { Letras } \\
\text { (p<0,05). *Momento em que houve adequação das contagens de bioindicadores de acordo com a legislação } \\
\text { vigente. BP - boas práticas de ordenha, fabricação e manipulação. }\end{array}$ & & & &
\end{tabular}

Para garantir inocuidade no consumo de queijos artesanais, além do monitoramento dos microorganismos preconizados na legislação, deve-se também atentar para a sanidade do rebanho. Assim, as ações de fiscalização e monitoramento devem abranger também o controle de zoonoses transmitidas pelos alimentos, especialmente a brucelose e tuberculose.

Apesar de ser uma produção artesanal, o processo de fabricação desse queijo deve ter rastreabilidade, havendo a necessidade de introdução de registros, que são sugeridos no Quadro1.

Os registros, além de auxiliar na detecção de situações que representam risco à saúde dos consumidores, podem também ser uma fonte de informação aos produtores na identificação de procedimentos que comprometem a qualidade sensorial dos queijos. São ferramentas importantes para auxiliar os fiscais na verificação e aplicação correta dos requisitos exigidos pela legislação vigente. 
Quadro 1. Principais etapas que devem ser controladas na cadeia de produção do queijo minas artesanal

\begin{tabular}{|c|c|c|c|}
\hline Etapa & $\begin{array}{l}\text { Risco contaminação / } \\
\text { infecção }\end{array}$ & Medidas preventivas & Registro \\
\hline $\begin{array}{l}\text { Aquisição de } \\
\text { animais }\end{array}$ & $\begin{array}{c}\text { Animal apresenta } \\
\text { doenças com risco para } \\
\text { a saúde pública }\end{array}$ & $\begin{array}{l}\text { Atestado de vacinação para } \\
\text { brucelose, febre aftosa e testes } \\
\text { negativos para brucelose e } \\
\text { tuberculose }\end{array}$ & $\begin{array}{l}\text { Data: Dados animal / } \\
\text { Resultados testes: }\end{array}$ \\
\hline $\begin{array}{l}\text { Sanidade do } \\
\text { rebanho }\end{array}$ & $\begin{array}{c}\text { Presença de doenças } \\
\text { no rebanho }\end{array}$ & $\begin{array}{c}\text { Vacinação para brucelose, } \\
\text { febre aftosa, teste para } \\
\text { brucelose e tuberculose }\end{array}$ & $\begin{array}{c}\text { Data/ Vacinação/ Teste / } \\
\text { Dados animais/ Resultados } \\
\text { testes } \\
\end{array}$ \\
\hline $\begin{array}{l}\text { Tratamento de } \\
\text { doenças }\end{array}$ & $\begin{array}{c}\text { Residuos de } \\
\text { medicamentos no leite }\end{array}$ & $\begin{array}{l}\text { Respeitar o periodo de } \\
\text { carência }\end{array}$ & $\begin{array}{c}\text { Data/Animal doente/ } \\
\text { Medicamento/ Periodo } \\
\text { carência }\end{array}$ \\
\hline Ordenha & $\begin{array}{l}\text { Contaminação do leite } \\
\text { com material estranho } \\
\text { (sujidades) }\end{array}$ & $\begin{array}{c}\text { Boas práticas na obtenção do } \\
\text { leite }\end{array}$ & $\begin{array}{c}\text { Hora higienização/ } \\
\text { Substâncias usadas / Horário }\end{array}$ \\
\hline Ordenha & $\begin{array}{c}\text { Mastite: } S \text {. aureus e } \\
\text { outros } \\
\text { Fezes e urina (grupo } \\
\text { coliforme, outros) }\end{array}$ & $\begin{array}{l}\text { Uso caneca telada/ desprezar } 3 \\
\text { primeiros jatos / CMT/ } \\
\quad \text { minimo mensal } \\
\text { Positivos: ordenha separada } \\
\text { até final do tratamento }\end{array}$ & $\begin{array}{c}\text { Teste usado/ Data / } \\
\text { Resultado por animal/ Destino } \\
\text { animal e do leite }\end{array}$ \\
\hline Água & $\begin{array}{l}\text { Contaminação das } \\
\text { instalações, leite e } \\
\text { higienização }\end{array}$ & $\begin{array}{l}\text { Cloração da água conforme } \\
\text { legislação vigente }\end{array}$ & $\begin{array}{l}\text { Data/ Forma de cloração/ } \\
\text { Medição do cloro/ Análise: }\end{array}$ \\
\hline $\begin{array}{l}\text { Fabricação } \\
\text { do queijo }\end{array}$ & $\begin{array}{c}\text { Tempo entre ordenha e } \\
\text { fabricação }\end{array}$ & $\begin{array}{c}\text { Iniciar a fabricação do queijo } \\
\text { até } 90 \text { dias do inicio da } \\
\text { ordenha }\end{array}$ & $\begin{array}{l}\text { Horário do início da } \\
\text { fabricação do queijo }\end{array}$ \\
\hline $\begin{array}{l}\text { Fabricação do } \\
\text { queijo }\end{array}$ & $\begin{array}{l}\text { Presença de animais e } \\
\text { insetos na queijaria }\end{array}$ & $\begin{array}{c}\text { Controle de pragas; estrutura } \\
\text { queijaria em boas condições } \\
\text { de vedação }\end{array}$ & $\begin{array}{c}\text { Controle de pragas/ } \\
\text { Local armadilhas/ } \\
\text { Data vistoria/ Medidas } \\
\text { tomadas }\end{array}$ \\
\hline $\begin{array}{l}\text { Fabricação do } \\
\text { queijo }\end{array}$ & $\begin{array}{l}\text { Utensilios e } \\
\text { equipamentos } \\
\text { contaminados }\end{array}$ & $\begin{array}{c}\text { Higienizar utensilios e } \\
\text { equipamentos antes, durante e } \\
\text { após fabricação }\end{array}$ & Método de higienização \\
\hline $\begin{array}{l}\text { Maturação/ cura do } \\
\text { queijo }\end{array}$ & $\begin{array}{c}\text { Presença de patógenos. } \\
\text { deteriorantes }\end{array}$ & $\begin{array}{c}\text { Maturar o queijo por um } \\
\text { periodo minimo estabelecido }\end{array}$ & Data inicio/Data final \\
\hline $\begin{array}{l}\text { Armazenar. } \\
\text { Transportar, } \\
\text { comercializar }\end{array}$ & Material estranho & $\begin{array}{l}\text { Embalagens, transporte: } \\
\text { recipiente fechado }\end{array}$ & $\begin{array}{l}\text { Quantidade de queijo/ Data } \\
\text { lote/ Destino }\end{array}$ \\
\hline Comercialização & Não identificação & $\begin{array}{c}\text { Rotulagem adequada: } \\
\text { identificar produtor, datas, } \\
\text { lote, informação nutricional, } \\
\text { outras }\end{array}$ & $\begin{array}{l}\text { Informação nutricional/ } \\
\text { análise do rótulo }\end{array}$ \\
\hline
\end{tabular}

Adaptado da Portaria $n^{\circ} 523$, de 3 de julho de $2002^{(16)}$.

\section{Conclusão}

A composição média dos queijos artesanais foi: $2,08 \pm 0,59 \%$ de cloreto de sódio, $27,46 \pm 3,17 \%$ de proteínas, $5,34 \pm 0,83 \%$ de cinzas, $30,10 \pm 3,67 \%$ de gordura e $35,39 \pm 8,11 \%$ de umidade. A gordura no extrato seco (GES) foi de $47,15 \% \pm 4,63 \%$ e a acidez de $1,97 \pm 1,42$ gramas de ácido láctico. Dessa 
forma, foram classificados como gordos e de baixa umidade.

As condições das propriedades mostraram-se deficientes nos aspectos relacionados à estrutura e às práticas sanitárias e o treinamento mostrou-se eficaz na redução das contagens de coliformes totais e E. coli, mas não de Staphylococcus coagulase positiva.

Não foi possível determinar um período de maturação mínimo que garantisse o atendimento à legislação para todos os micro-organismos, apesar de 12 dias de maturação serem suficientes para reduzir coliformes a níveis aceitáveis. Água não potável, higienização inadequada das mãos e ambientes são fontes de contaminação do leite e queijo. Para garantir a inocuidade do queijo artesanal, é necessário o reforço e a repetição dos treinamentos, controle da mastite, registro das atividades, rastreabilidade dos lotes, associados ao monitoramento com fiscalização regulares, além da exigência de as propriedades serem livres de doenças zoonóticas importantes para a saúde pública.

\section{Referências}

1. Pinto MS, Ferreira CLLF, Martins JM, Teodoro VAM, Pires ACS, Fontes LBA, Vargas PIR. Segurança alimentar do queijo minas artesanal do Serro, Minas Gerais, em função da adoção de boas práticas de fabricação. Pesqui. Agropec. Trop. 2009;39(4):342-347.

2. Dores MT, Nobrega JE, Ferreira CLLF. Room temperature aging to guarantee microbiological safety of Brazilian artisan Canastra cheese. Food Sci. Technol. 2013;33(1):180-185.

3. Silva J, Moraes CM, Silva CL, Sales GA, Keid LB, Matos PCM, Lara APSS, Moraes CCG. Brucella abortus detected in cheese from the Amazon region: differentiation of a vaccine strain (B19) from the field strain in the states of Pará, Amapá and Rondônia, Brazil. Pesqui. Vet. Bras. 2016;36(8): 705-710.

4. Starikoff KR. Inativação de Mycobacterium bovis durante a cura de queijo: definição de protocolo de estudo. 2011. 63 f. Tese (Doutorado) - Faculdade de Medicina Veterinária e Zootecnia, Universidade de São Paulo, 2011. Disponível em: http://www.teses.usp.br/teses/disponiveis/10/10134/tde-08032012-134518/pt-br.php

5. Azevedo ACA, Pereira JCO, Araújo LBA, Carvalho CT, Silva TC. Qualidade microbiológica do queijo de manteiga comercializado em supermercados e feiras livres da cidade de Natal-RN. Hig. Alim. 2017;31(266/267):91-95.

6. Rezende C, Tobal TM, Souza JN, Caldorin M, Marchetto AP. Avaliação microbiológica e físico-química de queijos minas-frescal artesanal comercializados no município de Votuporanga- SP. Hig. Alim. 2014;28(238/239):108-112.

7. Hipólito TMM, Monteiro RT, Hipólito LTM, Chaves AR, Veiga SMOM. Qualidade higiênico-sanitária do queijo minas artesanal do cerrado. Hig. Alim. 2014;28(238/239):158-162.

8. Brant LMF, Fonseca LM, Silva MCC. Avaliação da qualidade microbiológica do queijo-de-minas artesanal do Serro-MG. Arq. Bras. Med. Vet. Zootec. 2007;59(6):1570-1574.

9. Resende PHL, Mendonça EP, Melo RT, Coelho LR, Monteiro GP, Rossi DA. Aspectos sanitários do queijo Minas artesanal comercializado em feiras livres. Rev. Inst. Latic. Cândido Tostes. 2010; 377(65):36-42.

10. Chesca AC, Gonçalves YC, Santos ALS, D'Angelis CEM. Patógenos em queijo minas frescal e curado. Hig. Alim. 2015;29(242/243):90-93.

11. Silva N, Junqueira VCA, Silveira NFA, Taniwaki MH, Santos RFS. Gomes RAR, Okazaki MM. Manual de Métodos de Análises Microbiológicas de Alimentos. 3 ed. São Paulo - SP: Livraria Varela Ltda, 2007.

12. User's Guide Bax ${ }^{\circledR}$, System PCR assy with automated detection for bacterial screening, Silmington, DuPont Qualicon 2009.

13. Brasil. Ministério da Agricultura Pecuária e Abastecimento. Instrução Normativa nº 40, de 12 de dezembro

Cienc. anim. bras., Goiânia, v.19, 1-13, e-36499, 2018 
de 2005. Aprovar os Métodos Analíticos, Isolamento e Identificação da Salmonella na carne bovina, avicultura e produtos derivados de ovos. Diário Oficial da República Federativa do Brasil, Brasília, DF, 12 de dez. de 2005. Disponível em: http://extranet.agricultura.gov.br/sislegisconsulta/consultarLegislacao.do?operacao=visualizar\&id=15177

14. Brasil. Ministério da Agricultura Pecuária e Abastecimento. Instrução Normativa nº8, de 12 de dezembro de 2006. Oficializar os Métodos Analíticos Oficiais Físico-Químicos, para Controle de Leite e Produtos Lácteos. Diário Oficial da República Federativa do Brasil, Brasília, DF, 12 de dez. de 2006. Disponível em: https://wp.ufpel.edu.br/inspleite/files/2016/03/Instru\%C3\%A7\%C3\%A3o-normativa-n\%C2\%B0-68-de-12dezembro-de-2006.pdf

15. Ayres M. Aplicações Estatísticas nas Áreas das Ciências Biológicas e Médicas. Belém: Sociedade Civil Mamirauá, p.272, 2000.

16. Minas Gerais. Instituto Mineiro de Agropecuária - IMA Portaria $n^{\circ} 523$, de 3 de julho de 2002. Dispõe sobre as condições higiênico-sanitárias e boas práticas na manipulação e fabricação do queijo Minas artesanal. Palácio da Liberdade, Belo Horizonte, 3 de julho de 2002. Disponível em: http://www.ima.mg.gov.br/portarias/doc_details/212-portaria-no-523-de-3-de-julho-de-2002

17. Brasil. Ministério da Agricultura e Pecuária de Abastecimento. Portaria n 146, de 7 de março de 1996. Aprova os Regulamentos Técnicos de Identidade e Qualidade dos Produtos Lácteos. Diário Oficial da União, [da República Federativa do Brasil], Brasília, DF. 15 de agosto de 1996. Disponível em: http://extranet.agricultura.gov.br/sislegis-consulta/consultarLegislacao.do?operacao=visualizar $\& \mathrm{id}=1218$

18. Araújo RAB, Monteiro MS, Ferreira CLF, Ribeiro JrJI, Furtado MM. Diagnóstico socioeconômico, cultural e avaliação dos parâmetros físico-químicos e microbiológicos do queijo Minas artesanal da região de Araxá. 2004. Dissertação (Mestrado) Universidade Federal de Viçosa, Viçosa. Disponível em: http://www.locus.ufv.br/bitstream/handle/123456789/9041/texto\%20completo

.pdf? sequence $=1 \&$ isAllowed $=\mathrm{y}$

19. Martins JM. Características físico-químicas e microbiológicas durante a maturação do queijo minas artesanal da região do Serro. 2006. 158f. Dissertação (Mestrado) Universidade Federal de Viçosa, Viçosa. Disponível em: http://www.locus.ufv.br/bitstream/handle/123456789/499/ texto $\% 20$ completo.pdf? sequence $=1 \&$ isAllowed $=y$

20. Silva JG. Características físicas, físico-químicas e sensoriais do queijo Minas artesanal da Canastra, 2007. 198 p.: il. Dissertação (Mestrado). Universidade de Lavras, Lavras. Disponível em: http://repositorio.ufla.br/bitstream/1/3064/1/DISSERTA\%C3\%87\%C3\%83O_Caracter\%C3\%ADsticas\%20f \%C3\%ADsicas\%2C\%20f\%C3\%ADsicoqu\%C3\%ADmicas\%20e\%20sensoriais\%20do\%20queijo\%20Minas $\% 20$ artesanal $\% 20 \mathrm{da} \% 20 \mathrm{Canastra} . p d f$

21. Oliveira DF, Porto MAC, Bravo CEC, Tonial IB. Caracterização físico-química de queijos Minas artesanal produzidos em diferentes microrregiões de Minas Gerais. Oikos: Ver. Bras. Econ. Dom. 2013;24(2):185-196.

22. Lempk MW. Caracterização físico-química, microbiológica e tecnológica do queijo artesanal da microrregião de Montes Claros - MG, 2013. 91p. Dissertação (Mestrado) Universidade Federal de Minas Gerais, Belo Horizonte. Disponível em: http://www.bibliotecadigital.ufmg.br/dspace/ bitstream/handle/1843/NCAP-974PYC/marcus.pdf?sequence=1

23. Rocha AMP. Controle de fungos durante a maturação de queijo Minas Padrão. 2004. Dissertação (Mestrado) - Universidade Federal de Santa Maria, Rio Grande do Sul. Disponível em: http://repositorio.ufsm.br/bitstream/handle/1/5637/ANDREIAROCHA.pdf?sequence=1\&isAllowed=y

24. Minas Gerais. Decreto $n^{\circ} 44.864$, de $1^{\circ}$ de agosto de 2008. Altera o Regulamento da Lei n. 14.185, de 31 de janeiro de 2002, que dispõe sobre o processo de produção de Queijo Minas Artesanal. Palácio da Liberdade, Belo Horizonte, $1^{\mathrm{o}}$ de agosto de 2008. Disponível em: https://www.almg.gov.br/ consulte/legislacao/completa/completa.html?tipo $=$ DEC\&num $=44864 \&$ ano $=2008$ 
25. Brasil. Ministério da Saúde. Portaria $\mathrm{n}^{\circ}$ 2.914, de 12 de dezembro de 2011. Dispõe sobre os procedimentos de controle e de vigilância da qualidade da água para consumo humano e seu padrão de potabilidade. Diário Oficial da União, Seção 1, p. 266, 26 de dez. 2011. Disponível em: http://bvsms. saude.gov.br/bvs/saudelegis/gm/2011/prt2914_12_12_2011.html

26. Santos AS. Queijo Minas artesanal da microrregião do Serro-MG: efeito da sazonalidade sobre a microbiota do leite cru e comportamento microbiológico durante a maturação, 2010. S235q. Dissertação

(Mestrado) UFVJM, Diamantina. Disponível em: http://acervo.ufvjm.edu.br/jspui/ bitstream/1/721/1/aline_silva_santos.PDF

27. Minas Gerais. Lei 20.549 de 18 de dezembro de 2012. Dispõe sobre a produção e a comercialização dos queijos artesanais de Minas Gerais. 2012. Palácio da Liberdade, Belo Horizonte, 18 de dez. de 2012. Disponível em: https://www.legisweb.com.br/legislacao/?id=248559

28. Silva LCC, Beloti V, Tamanini R, D’ovidio L, Mattos MR, Arruda AMCT, Pires EMF. Rastreamento de fontes da contaminação microbiológica do leite cru durante a ordenha em propriedades leiteiras do Agreste Pernambucano. Semina: Ciênc. Agrár. 2011;32(1):267-276.

29. Medeiros MIM, Nader Filho A, Souza V, Melo PC, Ferreira LM, Canalejo LMM. Epidemiologia molecular aplicada ao monitoramento de estirpes de Staphylococcus aureus na produção de queijo minas frescal. Ci. Anim. Bras. 2013;14(1):98-105.

30. Costa HHS, Souza MR, Acúrcio LB, Cunha AF, Resende MFS, Nunes AC. Potencial probiótico in vitro de bactérias ácido-láticas isoladas de queijo-de-minas artesanal da Serra da Canastra, MG. Arq. Bras. Med. Vet. Zootec. 2013;65(6):1858-1866.

31. Bergdoll MS. Analytical Methods for Staphylococcus aureus. Int. J. F. Microbiol. 1990;10(2):91-99. 